\title{
Análisis genético molecular en niños con fibrosis hepática congénita
}

\author{
A molecular genetic analysis in 2 \\ children with congenital hepatic fibrosis
}

\begin{abstract}
$\mathrm{S}_{\mathrm{i}}^{\mathrm{r}}$ . Editor: El año 2004, nuestro grupo reportó en la Revista Médica de Chile, 5 niños con brosis hepática congénita (FHC), una manifestación clínica supuestamente tardía en la evolución de niños portadores de enfermedad renal poliquística autosómica recesiva (ARPKD por su sigla en inglés), describiendo el espectro clínico variable que incluía compromiso hepático y renal como los elementos más significativos ${ }^{1}$. La FHC es una enfermedad autosómica recesiva que clásicamente se asocia a enfermedad poliquística renal. De los 5 niños portadores de FHC, tres presentaron enfermedad poliquística renal, siendo ésta diagnosticada previo a la aparición de la enfermedad hepática, presentando un compromiso mayor del hígado, con una enfermedad más agresiva que requirió uso de shunts intrahepáticos transyugulares (TIPS) o derivaciones quirúrgicas portosistémicas para el manejo de su hipertensión portal. En contraste, los 2 niños que se diagnosticaron por presentar hepatomegalia persistente asintomática, presentaron función y tamaño renal normal y una evolución hepática más benigna ${ }^{1}$. En dicha publicación, señalamos que el gen comprometido, PKHD1 que se encuentra en el brazo corto del cromosoma 6 y que codifica para una proteína llamada fibrocistina, se postulaba como el receptor que participaría en la diferenciación biliar y de los túbulos colectores ${ }^{2,3}$ y que la variabilidad de la patología en su presentación (inicio prenatal, neonatal, infantil o juvenil) estaría relacionada a la expresión variable de mutaciones del mismo gen, como también al efecto de genes modificadores y factores ambientales, más que a mutaciones en diferentes genes ${ }^{4,5}$.

Posteriormente, en un esfuerzo conjunto con investigadores europeos se realizó el estudio genético correspondiente. Se realizó un análisis mutacional en los pacientes y sus padres del gen PKHD1 por DHPLC para los 66 exones codificantes de la proteína poliductina/fibrocistina de 4074 aminoácidos. La mayoría de los exones fueron amplificados como un solo fragmento, pero los exones más largos, 16, 27, 32, 58, 61 y 67 fueron divididos y amplificados en varios fragmentos sobrepuestos para limitar el tamaño de los amplicones. Las muestras que exhibían una elusión aberrante fueron sujetas a secuenciación en forma directa. De este modo se demostró que la niña descrita en el caso 3 de la publicación original presentaba 2 mutaciones: en el alelo paterno una mutación "missense"
\end{abstract}

Correspondencia a: Dr. Paul Harris D. Pontificia Universidad Católica de Chile, Facultad de Medicina, Departamento de Pediatría. Marcoleta 391, Santiago, Chile. C.P. 6510273. Tel: 3548177. Fax: 6331457. E mail: pharris@med.puc.cl 
c.107C >T en el exón 3 ocasionando un cambio de la treonina a metionina en la posición 36 de la secuencia aminoacídica (p.Thr36Met) y en el alelo materno una mutación "missense" c.1199T>C en el exón 15 (p.Leu400Ser), confirmando el diagnóstico clínico, ya que ambas mutaciones han sido descritas en $\mathrm{FHC}^{6}$. Dicho estudio garantiza la necesidad de consejo genético a los padres de la paciente en caso de un futuro embarazo.

La niña descrita como Caso Clínico 2, fue evaluada a través de análisis de ligandos ("linkage analysis") con marcadores del cromosoma 6p12, que es la zona donde se encuentra el gen PKHD1. Las tasas de recombinación para los marcadores informativos (D6S465 distal y M182 proximal) en el análisis del ADN de la familia (ambos padres y los 4 hijos) fue de $1.2 \mathrm{cM}$, lo cual es compatible con el diagnóstico clínico de FHC 6 . A la fecha no ha sido posible completar el análisis mutacional de esta paciente al igual que el de las otras 3 familias descritas.

Creemos que la colaboración internacional permitirá definir con precisión las mutaciones más frecuentes y poder entender la relación entre ellas y las significativas variantes en el curso clínico de la enfermedad. Adicionalmente, el conocimiento de estas mutaciones y su patrón de herencia, podrán ayudar en un correcto consejo genético.

\section{Paul R Harris', Felipe Cavagnaro S.M².}

Departamento de Pediatría, Unidades de Gastroenterología y Nutrición ${ }^{1}$ y Nefrología ${ }^{2}$, Facultad de Medicina, Pontificia Universidad Católica de Chile. Santiago de Chile.

\section{REFERENCIAS}

1. Harris P, Fodor D, Cavagnaro F, Di Egidio M, Duarte I, Fava M. Fibrosis hepática congénita: un espectro clínico variable. Casos clínicos. Rev Méd Chile 2004; 132: 733-41.

2. Ward C, Hogan M, Rossetti S, Walker D, Sneddon T, Wang X et al. The gene mutated in autosomal recessive polycystic kidney disease encodes a large, receptor-like protein. Nat Genet 2002; 30: 259-69.

3. Lens $\mathrm{X}$, Onuchic L, Wu G, Hayashi T, Daoust M, Mochizuki T et al. An integrated genetic and physical map of the autosomal recessive polycystic kidney disease region. Genomics 1997; 41: 463-6.

4. Mounif EL-Youssef, Yan M, Lujun X, Huang Y, Stelmach V, Grawford S. Increased expression of transforming growth factor B1 and Thrombospondin-1 in congenital hepatic fibrosis: possible role of the hepatic stellate cell. J Pediatr Gastroenterol Nutr 1999; 28: 386-91.

5. Guay-Woodford L, Gawani C, Musulman-Mroczeck E, Spear G, Guilot A, Berstein J. Diffuse renal cystic disease in children: morphologic and genetic correlations. Pediatr Nephrol 1998; 12: 173-82.

6. Bergmann C, Senderek J, Sediacek B, Peggiazoglou I, Pugla P, Eggermann T et al. Spectrum of Mutations in the Gene for Autosomal Recessive Polycystic Kidney Disease (ARPKD/PKHD1). J Am Soc Nephrol 2003; 14: 76-89. 